\title{
Failure After First Treatment
}

National Cancer Institute

\section{Source}

National Cancer Institute. Failure After First Treatment. NCI Thesaurus. Code C102635.

A lack of response to the first cycle of therapy. 